Int. J. Electrochem. Sci., 12 (2017) $2893-2908$

\title{
Influence of L-cystine as an Additive in the Negative Electrolyte on Performance of Vanadium Redox Flow Battery
}

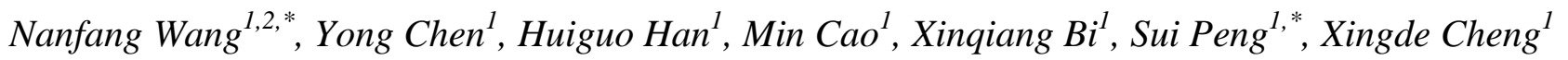 \\ ${ }^{1}$ Pangang Group Research Institute Co., Ltd., Panzhihua 617000, China \\ ${ }^{2}$ School of Chemistry and Chemical Engineering, Hunan Institute of Engineering, Xiangtan 411104, \\ China) \\ *E-mail: cdwnf@126.com (N. Wang), pengsui1976@yahoo.com.cn (S. Peng).
}

doi: $10.20964 / 2017.04 .51$

Received: 19 January 2017 / Accepted: 17 February 2017 / Published: 12 March 2017

\begin{abstract}
L-cystine (LC) was employed as an additive to inhibit crystallization of $\mathrm{V}$ (II) or V(III) specie in the negative electrolyte and extend the practical application of vanadium redox flow battery (VRB) at belowambient temperatures. UV-vis spectrometry showed LC has no effect on the absorption in the range of 300-800 $\mathrm{nm}$. Crossover the membrane testing indicated that LC can permeate from Negative side to Positive side across the Nafion 117. Static thermal stability testing showed LC can significantly inhibit precipitation of $\mathrm{V}(\mathrm{II}) \sim \mathrm{V}(\mathrm{IV})$ ions or $\mathrm{V}(\mathrm{V})$ in $1.8 \mathrm{M}$ vanadium electrolyte with $3.0 \mathrm{M} \mathrm{H}_{2} \mathrm{SO}_{4}$ at 5 or 50 ${ }^{\circ} \mathrm{C}$. It is found that $2-4 \mathrm{wt} \% \mathrm{LC}$ in vanadium electrolytes can lower viscosity compared to the blank electrolyte. Cyclic voltammetry (CV) and electrochemical impedance spectroscopy (EIS) show V(III) electrolyte with $2 \mathrm{wt} \%$ LC exhibits superior electrochemical activity and diffusion coefficient, compared with the pristine electrolyte. Introduction of LC into the negative electrolyte can obtain better performance of VRB with higher capacity retention $(91.04 \%$ vs. $84.3 \%)$ and energy efficiency $(75.77 \%$ vs. $72.27 \%)$ than the pristine electrolyte.
\end{abstract}

Keywords: Vanadium redox flow battery; L-cystine; Negative electrolyte; Thermal stability; Electrochemical activity

\section{FULL TEXT}

(C) 2017 The Authors. Published by ESG (www.electrochemsci.org). This article is an open access article distributed under the terms and conditions of the Creative Commons Attribution license (http://creativecommons.org/licenses/by/4.0/). 